\title{
EFFECT OF AMBIENT TEMPERATURE ON THE SHEAR BOND STRENGTH OF GLASS IONOMER LUTING AGENT- AN IN VITRO STUDY
}

\author{
Farah Khan'1, Raghu Raghav Agarwal2, Saher Khan ${ }^{3}$
}

${ }^{1}$ Assistant Professor, Department of Dentistry, Rajshree Medical Research Institute, Bareilly, Uttar Pradesh, India.

${ }^{2}$ Senior Lecturer, Department of Periodontology and Implantology, Kothiwal Dental College, Moradabad, Uttar Pradesh, India. 3Ph.D Student, Department of Microbiology, Era Medical College, Lucknow, Uttar Pradesh, India.

ABSTRACT
BACKGROUND
Ambient temperature is one of the important factors affecting the setting of GICs when used as a luting agent for cementation. This
in vitro study was planned to evaluate the effect of ambient room temperature on shear bond strength of GI luting agent.

\section{MATERIALS AND METHODS}

The occlusal surface of the extracted caries free $1^{\text {st }}$ mandibular right molar teeth was ground flat, which was embedded in the body of auto-polymerising resins. The impression of the tooth was made with the copper tube technique and cast was poured. A casting of dental alloy was fabricated with an attachment of $13 \mathrm{~mm}$ long and $3 \mathrm{~mm}$ thick on the occlusal surface. The glass ionomer was mixed according to manufacturer's instruction and applied on the tooth and casting under the static load of $2 \mathrm{~kg}$ and allowed to set for 10 minutes. The specimen was tested on the Instron universal testing machine to determine the bond strength. Each test was performed for 10 times under three ambient temperature conditions, viz. $16^{\circ} \pm 2^{\circ} \mathrm{C}$ (Group I), $24 \pm 2^{\circ} \mathrm{C}$ (Group II) and $34^{\circ} \pm 2^{\circ} \mathrm{C}$ (Group III). Data was analysed using SPSS 20.0 software. Kruskal-Wallis test followed by Mann-Whitney U test was used to analyse the data.

\section{RESULTS}

Mean shear bond strength of Groups I, II and III was $6.41 \pm 0.28,6.11 \pm 0.19$ and $5.85 \pm 0.16$ MPa respectively. Inter and between group differences were significant statistically $(\mathrm{p}<0.05)$.

\section{CONCLUSION}

With increasing ambient temperature, shear bond strength of GI luting agent showed a significant decrease. Further studies to recognise optimal temperature conditions are recommended.

\section{KEY WORDS}

Glass Ionomer Luting Agent, Shear Bond Strength, Ambient Temperature, Setting.

HOW TO CITE THIS ARTICLE: Khan F, Agarwal RR, Khan S. Effect of ambient temperature on the shear bond strength of glass ionomer luting agent- an in vitro study. J. Evolution Med. Dent. Sci. 2018;7(28):3199-3203, DOI: 10.14260/jemds/2018/720

\section{BACKGROUND}

Dental cements are widely used in dentistry with different clinical uses in dentistry like liners and base materials to protect the pulp from thermal, electrical and chemical effects, as root canal sealing agents, orthodontic bracket adhesives, pit and fissure sealants, core build up, temporary filling material to cover the cavity hermetically and protect the tooth from external effects, restorative materials and luting materials in adapting tooth to indirect restorations prepared out of mouth. The luting agents may be permanent or temporary depending on their physical properties and the planned longevity of the restoration. ${ }^{1}$

The setting reaction of GIC is an acid-base reaction between polyacid liquid and glass. ${ }^{2}$ The setting of the GICs can also be influenced by external factors like temperature, humidity, pressure and mixing time. ${ }^{3-6}$ This eventually has an impact on the physical properties, such as strength of the bond.

'Financial or Other Competing Interest': None.

Submission 29-05-2018, Peer Review 22-06-2018,

Acceptance 29-06-2018, Published 09-07-2018.

Corresponding Author:

Farah Khan,

Anupam Nagar, Aishbagh, Lucknow,

Uttar Pradesh, India.

E-mail:farahkhan.doc@gmail.com

DOI: $10.14260 /$ jemds $/ 2018 / 720$

\section{(c) (i) $\$$}

Hence, the present study was planned to evaluate the effect of ambient temperature on the shear bond strength of glass ionomer luting agents.

\section{MATERIALS AND METHODS}

An extracted caries free $1^{\text {st }}$ mandibular right molar tooth was taken (Fig. 1a). The metal base (ME Alloy, Dentsply, UK) having surface area of $1 \mathrm{~cm}^{2}$ and height of $12 \mathrm{~mm}$ was selected. The petroleum jelly was applied around the metal base. The RR auto-polymerising acrylic resins powder and liquid (Dentsply, India) was mixed in a ratio of 3: 1 and poured in a metal base. The tooth was cleaned and embedded in acrylic resin in metal base. It allowed to polymerise for 3 hours and removed from the base (Fig. 1b). The occlusal surface was ground flat and chamfer finishing line of $0.8 \mathrm{~mm}$ wide was prepared with tapered round end diamond disc of medium grit (Fig. 1c and 1d). An impression of tooth was made with copper band impression technique. A properly fitting copper band for a particular tooth was selected and vent holes were made on the upper end of the tube. Thermoseal floss (ICPA Health Product Ltd., India) was passed through these vent holes and tied (Fig. 1e). One end of the tube was plugged with the impression compound. The impression was made with Aquasil and catalyst (putty) and it is lined with Aquasil Ultra LV (DeguDent $\mathrm{GmbH}$, Rodenbacher, Germany) and poured with Kalrock die stone 
(Kalabhai Karsan Pvt. Ltd., Mumbai) (Fig. 1f and 1g). Disep (Die spacer) (Han Doe Chemical Co., India) was applied on the die (Fig. 1h). A wax pattern of $0.8 \mathrm{~mm}$ thickness was prepared on the tooth. An attachment of $3 \mathrm{~mm}$ thick and $13 \mathrm{~mm}$ long was attached on occlusal surface. The sprue former of 14 gauge $(1.7 \mathrm{~mm})$ (Dentsply) was also connected to the attachment and a reservoir was made (Fig. 1i). The stainless-steel casting ring was lined with Interdent ring liner (Interdent Opekarmiska 26) kept $3 \mathrm{~mm}$ short from the open end of the ring and was wet with water. Waxit (wetting agent for casting wax models) was used to increase the surface tension of the pattern. Deguvest Impact Investment Powder and Liquid were dispensed according to manufacturer's direction and mixed in vacuum mixing jar of Whipmix vacuum mixing machine. The mixed deguvent impact investment was filled into stainless steel casting ring and allowed to set for 30 minutes. The mold was placed in UGIN Dentaire burnout furnace preheated at $200^{\circ} \mathrm{C}$ for 20 minutes and increases the temperature upto $930^{\circ} \mathrm{C}$ for 2 hours for wax elimination. The hot casting ring is shifted from burnout furnace to Ducatron Induction casting machine. The ring is placed in the casting cradle in such a manner that the sprue adjoins the cradle. The alloy was melted on porcelain crucible by induction heating and casting was done.

After casting, the specimens were finished and polished with NP Alloy adjustment kit (Shofu, Japan) (Fig. 2a). HYBond glass ionomer CX cement (Shofu Inc., Japan) was mixed according to manufacturer's instructions and applied on the intaglio surface of the casting under the static load of $2 \mathrm{~kg}$ and allowed to set for 10 minutes (Fig. 2b and Fig. 2c). Once set, the specimens were tested by mounting them onto Instron universal testing machine (Blue Star, India) at a crosshead speed of $0.5 \mathrm{~mm} / \mathrm{min}$ to determine the bond strength of the specimens (Fig. 3). This test was performed for 10 times at each temperature $\left(16^{\circ} \pm 2^{\circ} \mathrm{C}\right.$ (Group I), $24^{\circ} \pm 2^{\circ} \mathrm{C}$ (Group II) and $34^{\circ} \pm 2^{\circ} \mathrm{C}$ (Group III).

\section{Statistical Analysis}

The data so collected was subjected to analysis using Statistical Package for Social Sciences (SPSS) version 20.0. On normality assessment asymmetry was found, hence a nonparametric evaluation plan was adopted. Data was analysed using Kruskal-Wallis test followed by Mann-Whitney U test. ' $P$ ' value less than 0.05 was considered to be indicative of statistically significant difference.

\section{RESULTS}

Shear bond strength ranged from 5.60 to $6.70 \mathrm{MPa}$ in different groups. In Group I $\left(16 \pm 2^{\circ} \mathrm{C}\right)$, mean shear bond strength was maximum (6.41 \pm 0.28 ; Median $6.55 \mathrm{MPa})$ followed by Group II $\left(24 \pm 2^{\circ} \mathrm{C}\right.$ ) (Mean 6.11 \pm 0.19 ; Median 6.10 $\mathrm{MPa})$ and minimum in Group III $\left(34 \pm 2^{\circ} \mathrm{C}\right)$ (Mean $5.85 \pm 0.61$; Median 5.85 MPa). Statistically, intergroup differences were significant $(H=15.976 ; p<0.001)$. On evaluating the between group differences too, all the between group differences were significant (Table 1; Fig. 4). On the basis of these observations, the order of shear bond strength in different groups was as follows: Group I > Group II > Group III.

\begin{tabular}{|c|c|c|c|c|c|c|c|}
\hline Sl. No. & Group & n & Mean & SD & Min & Max & Median \\
\hline 1. & I & 10 & 6.41 & 0.28 & 6.00 & 6.70 & 6.55 \\
\hline 2. & II & 10 & 6.11 & 0.19 & 5.80 & 6.40 & 6.10 \\
\hline 3. & III & 10 & 5.85 & 0.16 & 5.60 & 6.10 & 5.85 \\
\hline \multicolumn{7}{|c|}{ Table 1. Intergroup Comparison of Shear Bond Strength } \\
(MPa)
\end{tabular}

$\mathrm{H}=15.976(\mathrm{df}=2) ; \mathrm{p}<0.001$ (Kruskal-Wallis test)

$\mathrm{z}=2.21 ; \mathrm{p}<0.029$ (I vs. II), $\mathrm{z}=3.50 ; \mathrm{p}<0.001$ (I vs. III), $\mathrm{z}=2.670 ; \mathrm{p}=0.007$ (II vs. III) (Mann-Whitney U test)

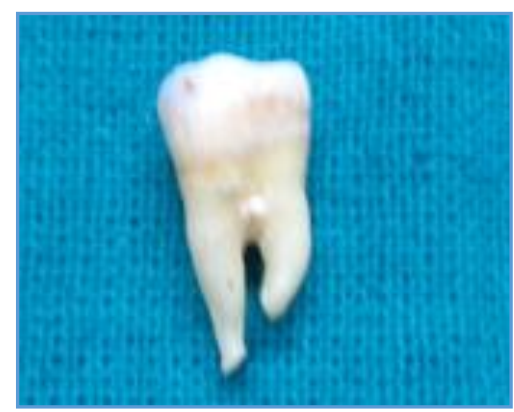

Figure 1a. Extracted Molar Tooth

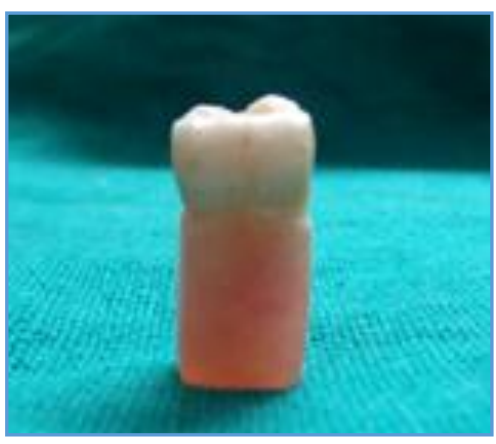

Figure 1b. The Tooth was Cleaned and Embedded in Autopolymerising Acrylic Resin

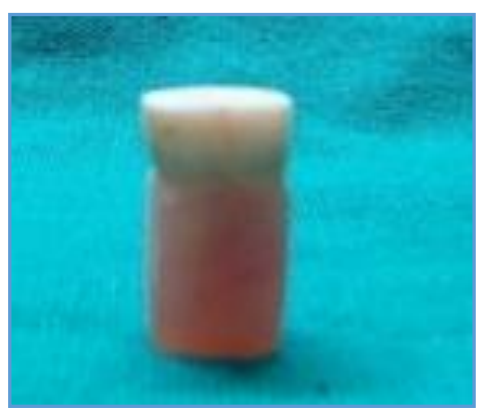

Figure 1c. The Occlusal Surface was Ground Flat

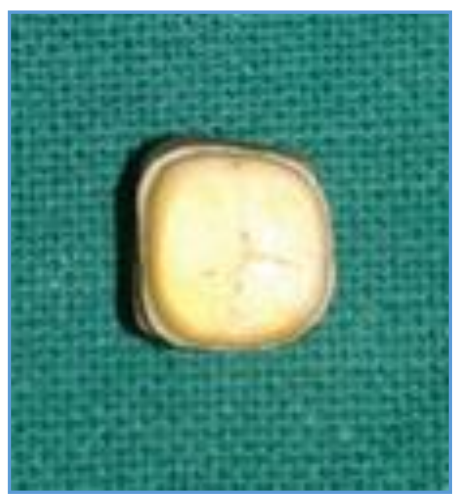

Figure 1d. Chamfer Finishing Line of $0.8 \mathrm{~mm}$ wide was Prepared 


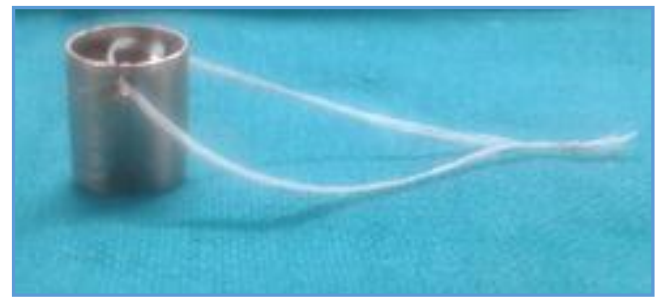

Figure 1e. Vent Holes were made on the Upper End of the properly fitting Copper Band for a particular Tooth. Thermoseal Floss was passed through these Vent Holes and Tied.

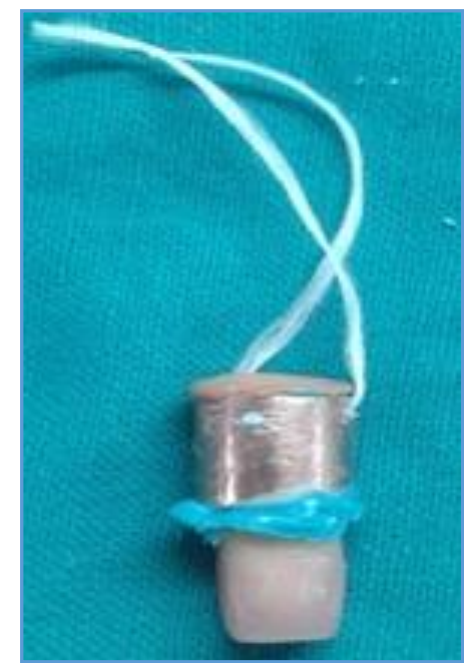

Figure 1f. One End of the Tube was plugged with the Impression Compound. The Impression was made with Aquasil and Catalyst (Putty) and it is lined with Aquasil Ultra LV.

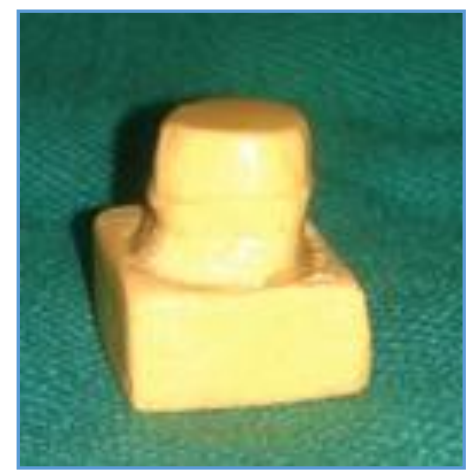

Figure 1g. Impression was poured with Ultrarock Die Stone

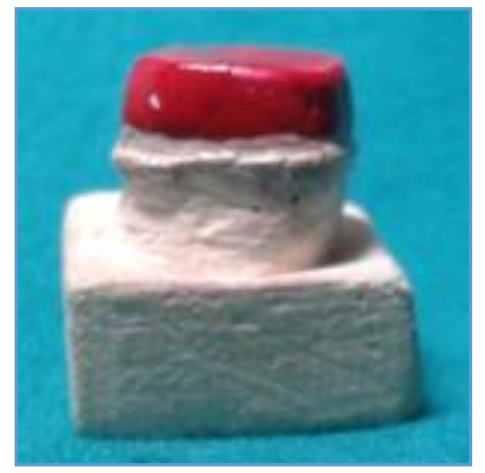

Figure 1h. Die Spacer was Applied

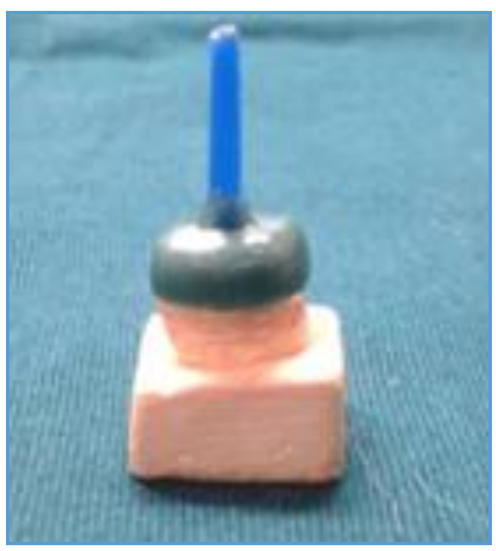

Figure 1i. A Wax Pattern with an attachment was prepared on the Tooth

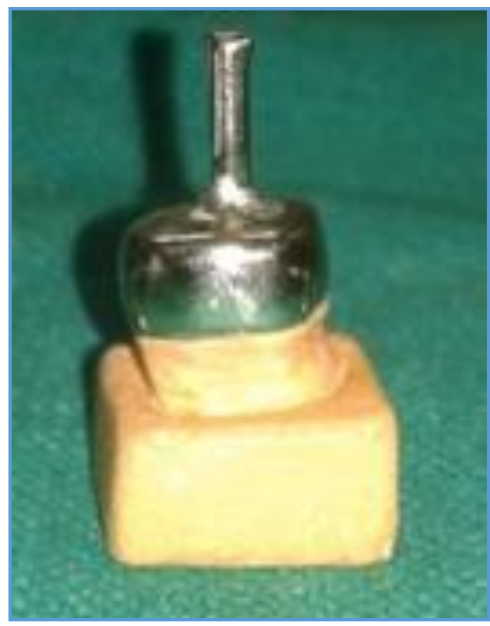

Figure 2a. The Casted Specimens were Finished and Polished

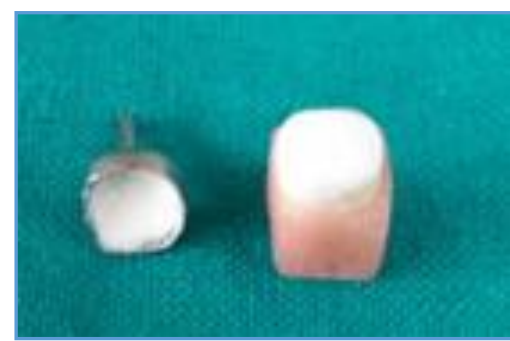

Figure $2 b$. GIC was applied on the Casting

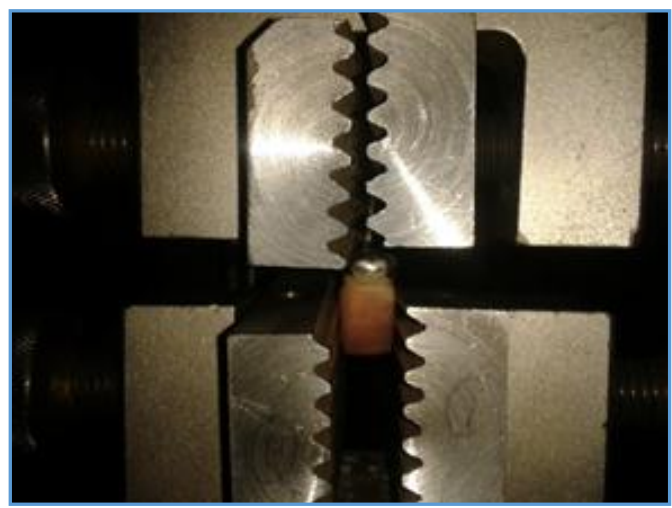

Figure 2c. The Static Load of $2 \mathrm{~kg}$ was applied and allowed to set for 10 Minutes 


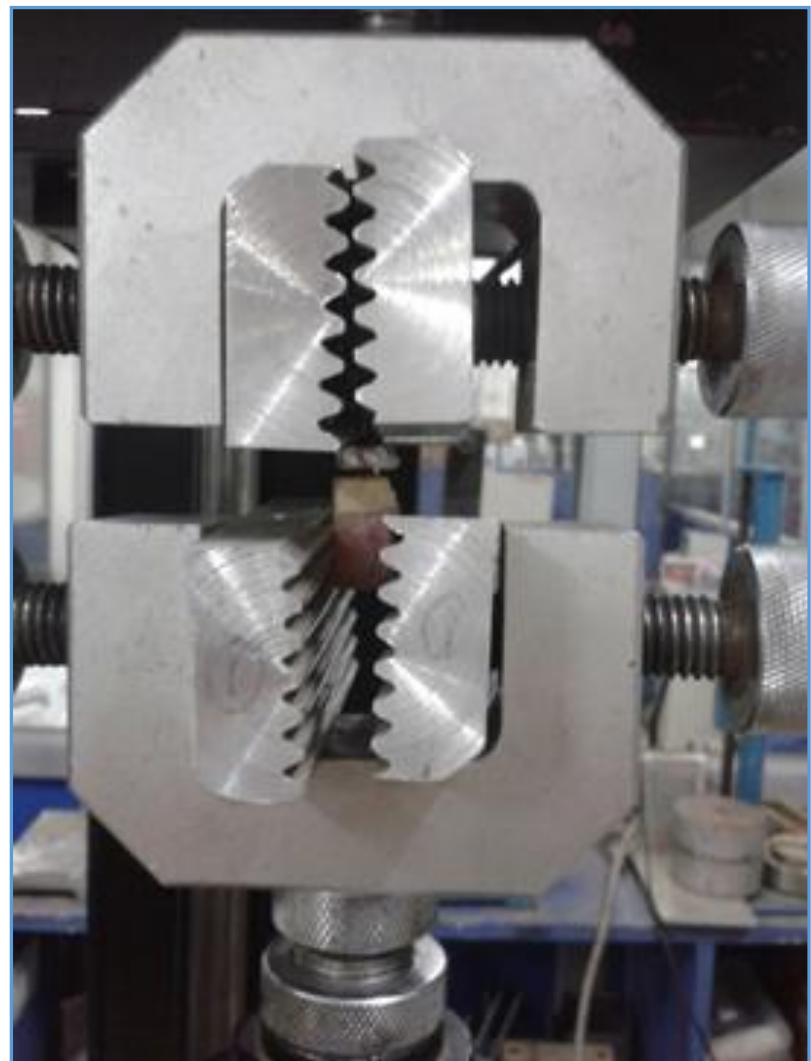

Figure 3. The Specimens were tested on Instron Universal Testing Machine to determine the Bond Strength of the Specimens

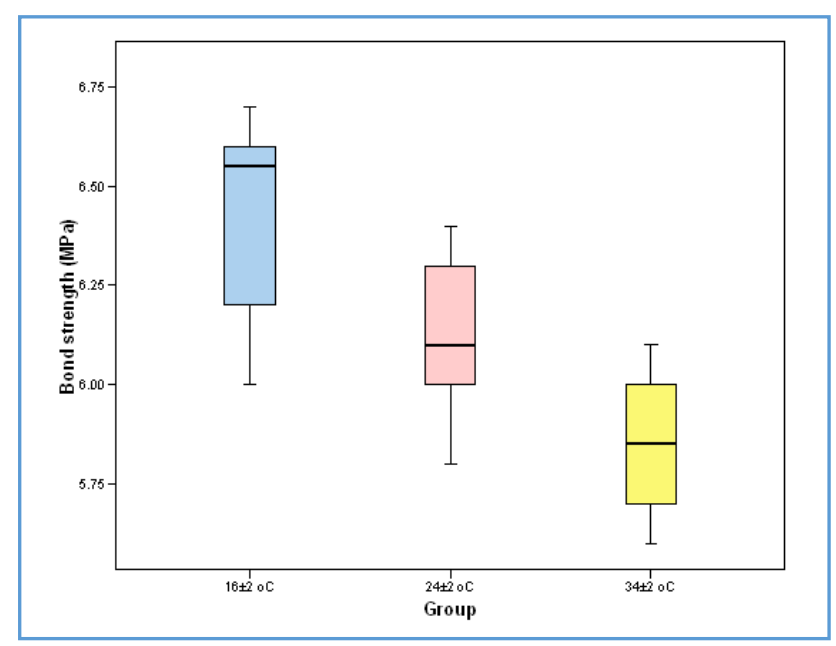

Figure 4. Box Plot showing dispersion of Bond Strength values at different Temperature Conditions

\section{DISCUSSION}

A number of studies evaluating the physical properties of luting agents have been conducted under room temperature ${ }^{7-}$ 9; however, recent evidence has indicated an effect of variable temperatures. ${ }^{10}$ Encouraged by this, the present study was carried out to evaluate the effect of variable temperature on the shear bond strength of glass ionomer luting agents. In present study, the selection of temperatures was done in consonance with the seasonal variation in temperature, specifically in tropical countries. In India during summer the average temperature is $34^{\circ} \pm 2^{\circ} \mathrm{C}$, whereas in winters it reaches to $16^{\circ} \pm 2^{\circ} \mathrm{C}$, whereas in spring it remains at $24^{\circ} \pm 2^{\circ} \mathrm{C}$. Considering the Indian climatic conditions, three different ambient temperatures i.e. $34^{\circ} \pm 2^{\circ} \mathrm{C}, 24^{\circ} \pm 2^{\circ} \mathrm{C}$ and $16^{\circ} \pm 2^{\circ} \mathrm{C}$ were selected for this study as these represent extreme temperature variations in India.

The inter group comparison in present study revealed an inverse relationship between increasing ambient temperature and bond strength. The loss in bond strength with increasing temperature can be explained on the basis of several theories. In a previous study, Bagheri ${ }^{10}$ has shown that setting of glass ionomer luting agents under variable temperature conditions results in difference in film thickness with film thickness showing a direct relationship with increasing temperature. It has been shown in a separate study that increasing film thickness of dental cement results in incomplete seating of the crowns, which could lead to increased marginal discrepancies thus. ${ }^{11}$ In effect this increase in marginal discrepancy might be responsible for loss of strength as observed in present study. Similar to results of present study, Patil et $\mathrm{al}^{5}$ also showed a decreasing trend of compressive and tensile strength in their experiment in which they used four different types of luting cements (Poly F, Liv Carbo, Fuji I, Fuji Plus) under variable temperature conditions of $23^{\circ} \mathrm{C}, 37^{\circ} \mathrm{C}$ and $50^{\circ} \mathrm{C}$ respectively. However, in their study, they could not find this difference to be statistically significant. The difference in findings of present study and that of Patil et $\mathrm{al}^{5}$ could be attributed to difference in type of physical property being evaluated and difference in temperature points taken for the purpose of study. In present study, we selected $16^{\circ} \mathrm{C}, 24^{\circ} \mathrm{C}$ and $34^{\circ} \mathrm{C}$ with a standard variability of $\pm 2{ }^{\circ} \mathrm{C}$, whereas Patil et al 5 took $23^{\circ} \mathrm{C}$, $37^{\circ} \mathrm{C}$ and $50^{\circ} \mathrm{C}$, moreover, the difference in type of luting cement could also be one of the factors resulting in difference. Temperature plays an important role in determining the bond strength, as it affects the molecular activity of the luting cement at the time of setting which affects its interaction with the surface to which it is being bonded. In a previous study, Cantoro et al showed that pre-cure temperature too has an effect on the bond strength of luting agents, thus implying that the ambient temperature, either in pre-cure or at the time of setting does have an impact on the physical properties, per se shear bond strength of the luting agents. These findings are important. However, the findings of present study must be considered in view of the fact that in present study homogeneous environment was tried to create to evaluate the effect of temperature on the bond strength and film thickness. Since this is an in-vitro study, other influencing factors like intrapulpal temperature, humidity, type of teeth and type of preparation are not taken in consideration. It would have been better if other cements that are widely marketed as luting cements would have been compared along with it. The effect of etching on the surface of substrate can also alter the bond strength and needs to be evaluated. Further, long term studies are directed towards invivo application of the present study and testing of adhesive resins for the same parameters.

\section{CONCLUSION}

In a controlled environment, change in ambient temperature showed a significant relationship with shear bond strength of Glass ionomer luting agents. 


\section{REFERENCES}

[1] Sumer E, Deger Y. Contemporay permanent luting agents used in dentistry: a literature review. Int Dent Res 2011;1(1):26-31.

[2] Pameijer $\mathrm{CH}$. A review of luting agents. Int J Dent 2012;2012:1-7.

[3] Strutz JM, White SN, Yu Z, et al. Luting cement-metal surface physicochemical interactions on film thickness. J Prosthet Dent 1994;72(2):128-32.

[4] Nazirkar G, Singh S, Badgujar M, et al. Effect of marginal sealant on shear bond strength of glass ionomer cement: used as a luting agent. Journal of International Oral Health: JIOH 2014;6(3):65-9.

[5] Patil SG, Sajjan MS, Patil R. The effect of temperature on compressive and tensile strengths of commonly used luting cements: an in vitro study. Journal of International Oral Health: JIOH 2015;7(2):13-9.
[6] Lad PP, Kamath M, Tarale K, et al. Practical clinical considerations of luting cements: a review. Journal of International Oral Health: JIOH 2014;6(1):116-20.

[7] Reisbick MH. Working qualities of glass-ionomer cements. J Prosthet Dent 1981;46(5):525-30.

[8] Oilo G. Bond strength of new ionomer cements to dentin. Scand J Dent Res 1981;89(4):344-7.

[9] Lacefield WR, Reindl MC, Retief DH. Tensile bond strength of a glass-ionomer cement. J Prosthet Dent 1985;53(2):194-8.

[10] Bagheri R. Film thickness and flow properties of resinbased cements at different temperatures. J Dent (Shiraz Univ Med Science) 2013;14(2):57-63.

[11] Kyrios DM, Duke ES, Windeler AS. Glass-ionomer cement film thickness and working time. J Prosthet Dent 1989;62(5):533-6. 